\title{
Knowledge Management Process of Germinated Brown Rice Production Community Enterprise
}

\author{
Worasit Wongadisai ${ }^{1}$, Sumalee Chanchalor ${ }^{2}$, Jariya Neanchaleay ${ }^{3}$ \\ ${ }^{\text {I}}$ Ph.D.student, King Mongkut's University of Technology Thonburi, Bangkok, Thailand, \\ worasit.wongadisai@mail.kmutt.ac.th \\ ${ }^{2}$ King Mongkut's University of Technology Thonburi, Bangkok, Thailand, isumalor@kmutt.ac.th \\ ${ }^{3}$ King Mongkut's University of TechnologyThonburi,Bangkok, Thailand, ijarleay@kmutt.ac.th
}

\begin{abstract}
The objective of this qualitative research was to investigate the knowledge management process of Germinated Brown Rice Production Community Enterprise in Sakon Nakhon, Northeastern region of Thailand, a major processing source. The sample was selected based on purposive sampling. It was BanNoijomsri Community Enterprise with effective knowledge management. Methodologies included interview, focus group, and participant and non-participant observations. Data were analyzed by content analysis. The results of this study indicated that 1). Knowledge identification focused on the knowledge used in production and production process development and community enterprise and business management, 2). Knowledge creation and acquisition were conducted inside and outside community enterprise through discussion and knowledge exchange with members, participation in training, and field trip with external agencies, 3). Knowledge storage was conducted by storing knowledge through personal recognition and important information note, 4). Knowledge distribution was conducted through discussion and knowledge sharing, demonstration, manual and process sign board preparation, and 5). Knowledge application was conducted by integrating knowledge and experience into new academic knowledge to obtain new body of knowledge. The key factors contributing to successful knowledge management were leadership and organizational culture.
\end{abstract}

KEYWORDS: Knowledge Management, Germinated Brown Rice, Community Enterprise

\section{Introduction}

Community enterprise is a community business related to production, service, or other (Small and Micro Community Enterprise (SMCE) Extension Act, 2005) that were done and managed by members of the community on the basis of using the combination of local knowledge, new knowledge, and appropriate technology to create greatest benefit for the community and create jobs and income to make the community prosperous (Pongpit 2013). Therefore, community enterprise is an important government's policy and is a foundation to develop economy, society, and life of people throughout the country. In year 2003, the government began the campaign One Tambon One Product (OTOP) to encourage each community in developing products according to its culture and lifestyle using local resources (OTOP selection manual 2016).

Germinated Brown Rice is an OTOP rice processed from the ancient local knowledge of Phu Tai Tribe in the Northeastern Region of Thailand which was continued for more than 200 years. In the past, germinated brown rice was made for poor people who lack rice or their barn is emptied before the harvest to eat, especially Sakon Nakhon in the Northeastern Region of Thailand. The germinated brown rice gained more popularity when the government encouraged and establish a community enterprise to produces and sells it. The germinated brown rice eating tradition had changed from the past as it was not a solution for famine but is now a product for health lovers and could also create jobs and income for people in the community as well, resulting in the expansion of germinated brown rice maker and the spread of this knowledge to other communities in Sakon Nakhon, making it promoted to be a provincial product of Sakon Nakhon recognized as one of the best germinated brown rice production areas, and advanced to be the germinated brown rice central cluster of Thailand (Sakon Nakhon Province 2015). However, from the 2017 community enterprise performance evaluation report, there is only 25.57 percent of community enterprises evaluated to be in good quality, while many encountered the issues of management, marketing, finance, product quality, and product consistency when mass producing (Thamma-Apiroam \& Udomwitid 2004 ; Chiarakul 2014). Therefore, related departments must have appropriate community enterprise and 
knowledge management in order to improve the performance of the community to sustain the management of community enterprise and develop it to be professions for later generations. Knowledge is one of the important foundations of an organization to be operational, and the organization must manage the knowledge appropriately and not too complicate in order to bring out the best potential from it (Schiuma 2012).

Knowledge management is a systematic effort to create, collect, disseminate, and utilize knowledge (Davenport \& Prusak, 1998). Knowledge is managed in an integrated manner with an aim to develop an organization and effectively solve the problems (Schiuma 2012) and in sustainable manner. It is value creation for the business and to maintain a competitive advantage (Tiwana 2001; Gharakhani \& Mousakhani 2012). Knowledge management is not only used in large business organizations focusing on knowledge management strategies but also in other kinds of organizations such as community organizations or community groups gathered together to systematically manage goods and services within the community (Chimplee 2012).

From its importance and problems, the researcher decided to study knowledge management process of the community enterprise. The selected study group is the Germinated Brown Rice Community Enterprise that continuously produces and sells germinated brown rice and received 5star standard certification. Performance evaluation on knowledge management process of Germinated Brown Rice Community Enterprise is to reflect its knowledge management process. In this study on knowledge management process of Germinated Brown Rice Community Enterprise, the researcher used synthesis of theories and concepts of corporate knowledge management (Tuamsuk et al. 12013; Durst \& Edvardsson 2012; Intasiri 2015; Mishra, \& Bhaskar 2011) as a framework, which consists of knowledge identification, knowledge creation and acquisition, knowledge storing, knowledge distribution, and knowledge application. The research result could be used as a guideline to encourage knowledge management in the community enterprise and could be used as a knowledge management improving model for other community enterprises, which would merit for the community enterprise and other related associates in supporting the strength of the community enterprise.

\section{Research Methodology}

This was a qualitative research targeting on studying the knowledge management process and other factors supporting Germinated Brown Rice Community Enterprise. The sample group used in this research is specified from Sakon Nakhon as this is a provincial product of Sakon Nakhon while the province is also the germinated brown rice central cluster of Thailand as well. The researcher used enterprise selection criterion concept from Songleknok et al.(2015), which are: 1. Characteristics of community enterprise including (1) The stablishment of community enterprise is the result of the integration of people in the community. (2) Production activity mainly uses local resources and labors. (3) The group management and the allocation of benefits were done through the board from member representatives. (4) The community enterprise has fund and budget for operating itself. (5) The community enterprise has the mean to produces and sells its products. 2 . The product is of high quality and meets 5-star product selection standard of OTOP. 3. The community enterprise was operating for more than 10 years. Moreover, the researcher also added the result of performance evaluation of corporate management and knowledge management for analysis as well to gain the appropriate study unit. From the result of the analysis on Ban-Noijomsri Community Enterprise, the community enterprise meets the criterion and rather more prominent than other groups.

The research instruments were a survey with focus group and participatory and nonparticipant observation, according to the knowledge management process, which consists of knowledge identification, knowledge creation and acquisition, knowledge storing, knowledge distribution, and knowledge application. The samples are the president, board members, and community enterprise members. The analysis of data was done by categorizing according to data types for data processing and to be used for content analysis in order to explain the knowledge management process of the sample community enterprise. 


\section{Result and Discussions}

\section{Background}

Ban-Noijomsri Germinated Brown Rice Community Enterprise is located at 222 group 4, BanNoijomsri, Hang Hong Sub-district, Mueang Sakon Nakhon District, Sakon Nakhon. The community enterprise produces and sells germinated brown rice with Pornpid Thongkon as the founder and the president. In the past, she received a suggestion from her relative to make germinated brown rice as it is the local knowledge her family inherit in the past, while also persuaded and learned how to make germinated brown rice for sale from Wirachai Unsakon, an ex-teacher at Sakon Nakhon Technical College as well. She tried and tested many times until getting the desired result. With this, she sees a way to create job inside the community. The government also has a revenue promotion policy and the Agriculture Office of Sakon Nakhon had also help promoting and created Ban-Noijomsri Germinated Brown Rice Community Enterprise, making germinated brown rice a product that brings income for the community and province members. This is because germinated brown rice contains high nutrition value, has GABA that could nurture the brain, could help preventing cancer, and contains many necessary vitamins and minerals (Nakornriab 2012). Currently, Ban-Noijomsri Germinated Brown Rice Community Enterprise is considered a high quality germinated brown rice production site of Sakon Nakhon which received 5-Star Outstanding OTOP Product Award and also certified from National Agricultural and Food Standards. The community enterprise had produced and sell germinated brown rice and rice products under the brand "Inthanin."

\section{Knowledge Management Process}

Knowledge Management Process of Ban-Noijomsri Germinated Brown Rice Community Enterprise consists of the following stages.

\subsection{Knowledge Identification}

Knowledge identification is an identification of the target required knowledge. Knowledge identification was mostly done by either formal or informal discussion of the leader and members focusing on how to use the knowledge in production and development of germinated brown rice as well as the knowledge for group management and business management. In this case (Bunpetch 2014), it is suggested that knowledge identification should be done to see the clear image and method of process, which the shared vision between members and responders is necessary to let the organization efficiently and effectively make knowledge management and resources layout.

\subsection{Knowledge Creation and Acquisition}

Knowledge acquisition could be done both inside and outside the group. From the inside, it could be done by discussion, asking, and exchanging information among the members or consulting the specialists inside the group, which is mostly a tacit knowledge. From the outside, it could be done by participating in a training program, participating in a seminar, visiting and workplace. The knowledge acquired from outside the group was passed down as explicit knowledge which could be used to create new knowledge using social cycle process (Nonaka a \& Tekeuchi 1995) for learning together, leading to the organization practices.

\subsection{Knowledge Storage}

Knowledge storage is mostly done by the memory of members as the original local knowledge. Some of it was also stored in the form of notes and also inside computers, but is not orderly and complete. The data stored is including record the rules and regulations of the group, production process, yield record and sales data. (customer list and sales), and also financial accounting records as well. These data were recorded and stored by the leader. This discovery is in accordance with Tuamsuk et al. (2013). Knowledge storage of the community is not systematically as each member collect the data by themselves. From the observation, there is not much knowledge stored and would only appear in the notes such as the knowledge of production process and usage of material. 


\subsection{Knowledge Distribution}

The group regularly distribute the knowledge within themselves. This includes the original knowledge and new knowledge. These knowledge would be distributed through speaking, teaching, suggesting, and demonstrating. Distribution by elaborate demonstration would make the receiver understand more (Chimplee 2012). Other than this, the knowledge was also distributed through manual books and process signs as well. The group focuses on participatory process and social interaction of the members, which could increase the method of distribution (Tsai 2002) of thoughts, which is an inside knowledge that would lead to corporal performance improvement (Hsiao 2013).

\subsection{Knowledge Application}

From the study, it was found and applying original knowledge and experience with new academic knowledge from outside could create new knowledge and could be used to improve working skills, production process, and developing new products with mutual counseling, resulting in the creation of new skills according to Tuamsuk et al. (2013). The success of the community business was created from systematically application and combination of local knowledge with and academic knowledge, thus allow further development of knowledge.

3. Important factors affecting knowledge management were leadership and organizational culture. From the study, the leader of Ban-Noijomsri Germinated Brown Rice Community Enterprise is capable and knowledgeable and also accepted by the members. The leader acts as the central of every operation within the group, influencing the decision of the group, encouraging knowledge management, and could pass down knowledge appropriately, which is in the accordance of Songleknok et al. (2015). The leader has an important role in continuously encouraging and managing the community enterprise to be able to continue doing business. The role of the leader of a community enterprise could be divided into 3 sides including being the director, supporter, and organizational culture network coordinator (Rukkarnsiumas et al. 2014). The leader will encourage unity within the group by including them in administration and problem solving, exchanging information, and relying on each other as mentioned by Keyser (2004) that organizational culture that encourages knowledge management is the organizational culture of knowledge sharing as well as making the organization atmosphere where the members are honest, have mutual target and interest, realized on mutual important tasks, and sharing knowledge together, which would affect the success of the organization knowledge management.

\section{Conclusions}

This study aimed to investigate knowledge management and factors supporting the knowledge management of the community enterprise according to the knowledge management process. The target of this research is to study the knowledge management process of the sample community enterprise. The study indicated that the sample community enterprise has the knowledge management following the knowledge management process which the members participate in the meeting, knowledge exchange, knowledge storing, and knowledge application by integrating original knowledge with new knowledge. The leadership factor and organizational culture factor that supporting mutual learning are the factors that would support the success of knowledge management of the community enterprise. This research result should be useful for community enterprises and associates related to their development and the researcher also hope that this study would be used for improving the performance of community enterprises as they are a type of organization that strengthens the community by combining the activities of economy, social, culture, and environment altogether.

\section{References}

Chiarakul, T. 2014. "The Problems and the Adaptation of OTOP to AEC.” Executive Journal 34(1): 177-196.

Chimplee, K. 2012. "Knowledge Management Models for Local Wisdom in Wickerwork Handicrafts: A Case Study of Local Community Enterprises in Nakhon Ratchasima Province." PhD diss., National Institute of Development Administration. Thailand. 
Davenport, T.H. and Prusak, L., 1998. Working Knowledge: How Organization Manage What They Know. Cambridge, MA: Harvard Business School Press.

Department of Agricultural Extension. 2005. "Small and Micro Community Enterprise (SMCE) Extension Act." Accessed February 20, 2016. https://www2.moac.go.th/ewt_news.php?nid=4062\&filename=index.

Durst, D. \& Edvardsson, I.2012. "Knowledge Management in SMEs: a Literature Review." Journal of Knowledge Management 16(6); 879-903. doi.org/10.1108/13673271211276173.

Gharakhani, D. \& M. Mousakhani, M. 2012. Knowledge Management Capabilities and SMEs' Organizational Performance. Journal of Chinese Entrepreneurship 4(1): 35 - 49. doi.org/10.1108/17561391211200920

Hsiao,Y., Chen, C., \& Chang, S. 2011. "Knowledge Management Capacity and Organizational Performance: the Social Interaction View." International Journal of Manpower 32(5/6): 645 -660. doi.org/10.1108/01437721111158242.

Intasiri, N. 2015. "Knowledge Management of Role-Model Farmers in Premium-Grade Beef Production." Veridian EJournal, Silpakorn University 8(4): 85-95.

Keyser, Richard Lewis. 2004. "Assessing The Relationship Between Knowledge Management and Plant Performance At The Tennessee Valley Authority." PhD Diss. The University of Alabama.

Mishra, B. \& Bhaskar, A. 2011. "Knowledge Management Process in Two Learning Organisations.” Journal of Knowledge Management 15 (2): 344 - 359. Doi.org/10.1108/13673271111119736.

Nakornriab, M. 2012. "Health Benets of Germinated Brown Rice and Germinated Prabolied Rice." The Science journal of Phetchaburi Rajabhat University 9(1): 69-79.

Nonaka, I. \& Takeuchi, H. 1995. "The Knowledge Creating Company” New York. Oxford University Press.

OTOP selection manual, 2016. "OTOP Product Champion." Accessed March 16, 2016. http://www.oic.go.th/ FILEWEB/CABINFOCENTER11/DRAWER022/GENERAL/DATA0000/00000012.PDF

Pongpit, S. 2013. "Community Enterprise is not Community Business." Community Enterprises: Economic Mechanism for Grass Root, 6th ed. N. Petprasert, and P. Wongkul, Ed. 205-219. Bangkok: Edison Press Production.

Rukkarnsi, S., Siripanumas, P., \& Pholcharoen. S. 2014. "Leadership Roles on Knowledge Management Process in Successful Community Enterprise Under the Project of the 5 Stars Award (OTOP) in Buriram: Lessons Learned." Rajabhat Maha Sarakham University Journal. 8(3): 139-151.

Sakon Nakhon Province. 2016. "Summary Information of Sakon NakhonProvince, Thailand.” Accessed March $16,2016$. http://www.sakonnakhon.go.th/th/etc/plan/chapter3.pdf.

Schiuma, G. 2012. "Managing Knowledge for Business Performance Omprovement." Journal of Knowledge Management 16(4): 515 - 522. doi.org/10.1108/13673271211246103.

Songleknok, S., Loipha, S. \& Vongprasert, C. 2015. "Knowledge Management Process of Indigo Dyed Cloth Community Business." Khon Kaen University Research Journal (Graduate Studies) 15(3):1-14.

Thamma-Apiroam, R. \& Udomwitid, S. 2004. "An Approach for OTOP Development in the North Eastern Region of Thailand." Research Project. Kasetsart University.

Tiwana, A. 2003. The Knowledge Management Toolkit: Practical Techniques for Building a Knowledge Management System. Atlanta: Prentice-Hall.

Tsai, W. 2002. "Social Structure of 'Coopetition' Within a Multiunit Organization: Coordination, Competition, and Intraorganizational Knowledge Sharing.” Organization Science 13(2): 179-90. Doi.org/10.1287/orsc.13.2.179.536.

Tuamsuk, K., Phabu, T., \& Vongprasert, C. 2013. "Knowledge Management Model of Community Business: Thai OTOP Champions.” Journal of Knowledge Management 17(3): 363-378. Doi.org/10.1108/JKM-10-2012-0321. 